\title{
Measurement and correlation for the solid solubility of non-steroidal anti-inflammatory drugs (NSAIDs) in supercritical carbon dioxide
}

\author{
Chie-Shaan Su, Yan-Ping Chen* \\ Department of Chemical Engineering, National Taiwan University, Taipei, Taiwan, ROC
}

Received 12 June 2007; received in revised form 8 August 2007; accepted 9 August 2007

\begin{abstract}
The solubilities for three non-steroidal anti-inflammatory drugs (NSAIDs) of nabumetone, phenylbutazone and salicylamide in supercritical carbon dioxide were measured in this study using a semi-flow type apparatus. The experimental data were taken at $308.2,318.2$ and $328.2 \mathrm{~K}$, over the pressure range from 10 to $22 \mathrm{MPa}$. The measured results were then correlated using semi-empirical equation presented by Chrastil, and that presented by Mendez-Santiago and Teja. With optimally fitted parameters, these two equations yielded satisfactory results where the average absolute relative deviation (AARD) was below 7\%. Furthermore, the solid solubilities of these three compounds and seven other NSAIDs in supercritical carbon dioxide were correlated by applying the regular solution model coupled with a Flory-Huggins term. The solution model, which has fewer parameters than the semi-empirical equations, yielded comparable correlation results. The parameters in the solution model could be generalized for the specific group of NSAIDs. Finally, the predicted solubilities of 10 NSAIDs in supercritical carbon dioxide were demonstrated to be reliable.
\end{abstract}

(C) 2007 Elsevier B.V. All rights reserved.

Keywords: Solid solubility; Supercritical carbon dioxide; Experiment; Correlation

\section{Introduction}

Supercritical fluid (SCF) technology, recognized as a green process, is applied in diversified fields of extraction, reaction, particle formation and material processing [1,2]. Carbon dioxide has been widely employed for the formation of micronized pharmaceutical compounds [3-6]. Various physical properties such as diffusion coefficient or solubility for supercritical fluid mixtures are crucial to the efficient design of industrial processes. Experimental solid solubility data in supercritical $\mathrm{CO}_{2}$ have been reviewed by several authors [7-9]. It is observed that more experimental data are still required for specialty chemicals and there is a need for generalized correlation models.

We have previously measured the solid solubilities of aromatic compounds in supercritical $\mathrm{CO}_{2}$ [10]. In this study, we used the similar semi-flow apparatus to measure the solid solubilities of nabumetone, phenylbutazone and salicylamide in supercritical $\mathrm{CO}_{2}$ at temperatures of $308.2,318.2$ and $328.2 \mathrm{~K}$, over the pressure range from 10 to $22 \mathrm{MPa}$. These three com-

\footnotetext{
* Corresponding author. Fax: +88622362 3040.

E-mail address: ypchen@ntu.edu.tw (Y.-P. Chen).
}

pounds are non-steroidal anti-inflammatory drugs (NSAIDs) with analgesic and antipyretic properties and are used to treat fever, headache and pain associated with colds, influenza and arthritis. No solid solubility data for these compounds in supercritical $\mathrm{CO}_{2}$ seem to have been reported in literature. The results of this study thus supply new data for further engineering design and theoretical modeling. The measured solid solubility data were firstly correlated using the three-parameter semiempirical equation presented by Chrastil [11], or that presented by Mendez-Santiago and Teja. [9]. Solid solubility data in supercritical fluids have also been correlated by solution models [12]. Our recent studies applied the regular solution model coupled with a Flory-Huggins term to correlate the solubilities of biological and pharmaceutical systems with satisfactory accuracy $[13,14]$. One advantage of the solution model approach is that the parameters might be able to be generalized and that prediction of solid solubilities might be possible. It was pointed out [14] that, rather than using a single set of universally correlated parameters, the generalized parameters in the solution model could be presented for different groups of compounds with specific chemical structures. The grouping of generalized parameters would effectively improve the prediction accuracy. The measured solid solubilities of three pharmaceutical compounds in 
this study, together with those data from literature for seven other NSAIDs, were correlated using the generalized solution model. It was intended to demonstrate that the solution model approach provides a feasible way for predicting the solubilities of complex compounds in supercritical $\mathrm{CO}_{2}$.

\section{Experimental}

\subsection{Chemicals}

Carbon dioxide was purchased from Liu-Hsiang Gas Co. (Taiwan) with a minimum purity of $99.8 \%$. Nabumetone $\left(\mathrm{C}_{15} \mathrm{H}_{16} \mathrm{O}_{2}\right)$, phenylbutazone $\left(\mathrm{C}_{19} \mathrm{H}_{20} \mathrm{~N}_{2} \mathrm{O}_{2}\right)$, salicylamide $\left(\mathrm{C}_{7} \mathrm{H}_{7} \mathrm{NO}_{2}\right)$ and salicylic acid $\left(\mathrm{C}_{7} \mathrm{H}_{6} \mathrm{O}_{3}\right)$ were purchased from Sigma-Aldrich Co. with a minimum purity of $99 \%$. These chemicals were used without further purification. The chemical structure and physical properties of nabumetone, phenylbutazone and salicylamide are listed in Table 1.

\subsection{Experimental apparatus and procedures}

A semi-flow type apparatus used in this study for measuring solid solubility in supercritical $\mathrm{CO}_{2}$ is shown in Fig. 1. The experimental system included three parts: (I) the feed of supercritical $\mathrm{CO}_{2}$, (II) the equilibrium between the solid and the supercritical phases and (III) the analysis of experimental results. Pure $\mathrm{CO}_{2}$ was liquefied to $273.2 \mathrm{~K}$ by a cooler and then was compressed to the desired pressure by a HPLC pump (Thermo Separation Product). The pressure was regulated by a back pressure regulator. The high pressure $\mathrm{CO}_{2}$ passed through the pre-heating coil, which was immersed in a water bath. It was then charged into the pre-equilibrium and equilibrium cells. Both cells had a volume of $75 \mathrm{~cm}^{3}$ where $10 \mathrm{~g}$ drug sample was packed with glass beads. The cells were plugged at their ends with glass wool or filter to avoid any physical entrainment. The temperature and pressure were measured using a calibrated thermocouple and a Druck pressure transducer (PTX 610), respectively. The resolutions for temperature and pressure measurements were $\pm 0.1 \mathrm{~K}$ and $\pm 0.01 \mathrm{MPa}$, respectively.

After the equilibrium cell, supercritical $\mathrm{CO}_{2}$ was expanded to atmospheric pressure through a needle valve wrapped with heating tape. The temperature of the heating tape was kept in the temperature range of $10-20 \mathrm{~K}$ above the melting point of the drug solid in order to avoid precipitation and blockage in the line. After the expansion, solid was separated from the gas phase and was dissolved into a flask with organic solvent. Residual solute in the line was recovered by further delivery of organic solvent. The sampling line was then purged by air to remove organic solvent. The total volume of $\mathrm{CO}_{2}$ flow was measured by a wet test meter (Ritter TG05). A HPLC system equipped with UV-VIS detector (Jasco UV-975) was used to analyze the concentration of the organic solution in the flask. In this study, ethyl acetate was chosen as the solvent. A sharp absorption peak in the UV-VIS detector for nabumetone, phenylbutazone and salicylamide was observed at the band of 263, 249 and $305 \mathrm{~nm}$, respectively. Calibrations for the UV analyses were made before the experiments using standard solutions of known concentrations. In each experiment, at least four measurements were taken at a given temperature and pressure. Repeated measurements were taken at various effluent $\mathrm{CO}_{2}$ flow rates between 3 and $10 \mathrm{~L} / \mathrm{h}$ at atmospheric conditions. These flow rates had no effect on solid solubility

Table 1

Physical properties of nabumetone, phenylbutazone and salicylamide

\begin{tabular}{|c|c|c|c|c|c|}
\hline Compound & Structure & Formula & Molecular weight $(\mathrm{kg} / \mathrm{mol})$ & $T_{\mathrm{m}}(\mathrm{K})$ & Purity (\%) \\
\hline Phenylbutazone & & $\mathrm{C}_{19} \mathrm{H}_{20} \mathrm{~N}_{2} \mathrm{O}_{2}$ & 0.3083 & $378.58[22,23]$ & $>99$ \\
\hline Salicylamide & & $\mathrm{C}_{7} \mathrm{H}_{7} \mathrm{NO}_{2}$ & 0.1371 & $413.58[22,23]$ & $>99$ \\
\hline
\end{tabular}




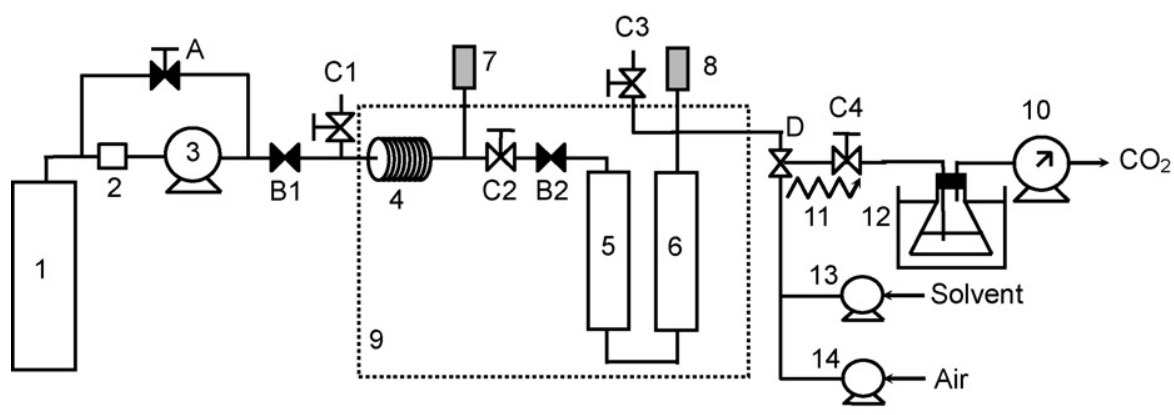

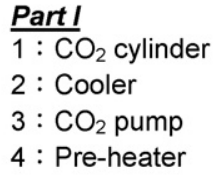

Valve description

A : Back pressure regulator

$B$ : Check valve

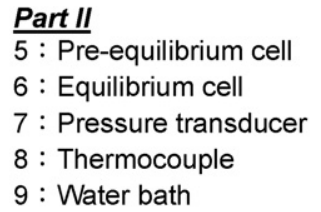

Part III

$10:$ Wet test meter

11 : Heating tape

12 : Solvent cold trap

13 : Solvent delivery pump

14 : Air pump

Fig. 1. Schematic diagram of the experimental apparatus.

measurements, and the experimental results were confirmed as equilibrium data.

\section{Results and discussion}

\subsection{Experimental results}

The reliability of the experimental apparatus and procedures were preliminarily confirmed by measuring the solubility of salicylic acid in supercritical carbon dioxide and comparing with literature data [15-17]. The results are shown in Fig. 2 where satisfactory agreement between various measurements was observed.

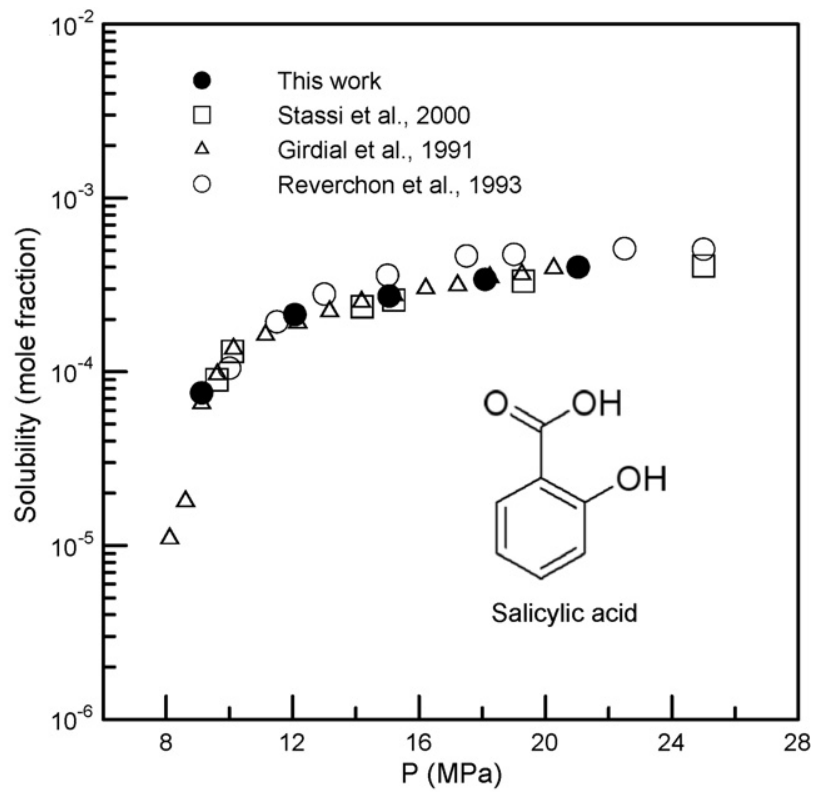

Fig. 2. Comparison of solubility data of salicylic acid in supercritical carbon dioxide at $313 \mathrm{~K}$.
The isothermal solid solubility data $(308.2,318.2$ and $328.2 \mathrm{~K}$ ) of three NSAIDs (nabumetone, phenylbutazone and salicylamide) in supercritical carbon dioxide were measured over the pressure range from 10 to $22 \mathrm{MPa}$. The equilibrium mole fractions of these solid compounds in the supercritical phase are listed in Tables $2-4$, respectively. Repeated measurements at various $\mathrm{CO}_{2}$ flow rates had been carried out in this study. The reported equilibrium solubilities showed satisfactory reproducibility. It was observed that the solubility increases

Table 2

Solubilities of nabumetone (2) in supercritical carbon dioxide (1)

\begin{tabular}{llll}
\hline$T(\mathrm{~K})$ & $P(\mathrm{MPa})$ & $y_{2}$ & S.D. \\
\hline 308.2 & 10.0 & $5.56 \mathrm{E}-04$ & $9.2 \mathrm{E}-06$ \\
& 12.0 & $7.93 \mathrm{E}-04$ & $1.5 \mathrm{E}-05$ \\
& 14.0 & $9.84 \mathrm{E}-04$ & $1.6 \mathrm{E}-05$ \\
& 16.0 & $1.14 \mathrm{E}-03$ & $2.8 \mathrm{E}-05$ \\
& 18.0 & $1.31 \mathrm{E}-03$ & $3.5 \mathrm{E}-05$ \\
& 20.1 & $1.46 \mathrm{E}-03$ & $2.8 \mathrm{E}-05$ \\
& 22.0 & $1.60 \mathrm{E}-03$ & $4.0 \mathrm{E}-05$ \\
318.2 & 10.1 & $2.34 \mathrm{E}-04$ & $5.2 \mathrm{E}-06$ \\
& 12.1 & $6.64 \mathrm{E}-04$ & $1.4 \mathrm{E}-05$ \\
& 14.0 & $9.77 \mathrm{E}-04$ & $2.5 \mathrm{E}-05$ \\
& 16.1 & $1.32 \mathrm{E}-03$ & $2.1 \mathrm{E}-05$ \\
& 18.0 & $1.61 \mathrm{E}-03$ & $3.4 \mathrm{E}-05$ \\
& 20.1 & $1.91 \mathrm{E}-03$ & $2.9 \mathrm{E}-05$ \\
328.2 & 22.0 & $2.14 \mathrm{E}-03$ & $6.0 \mathrm{E}-05$ \\
& 10.1 & $3.93 \mathrm{E}-05$ & $7.6 \mathrm{E}-07$ \\
& 12.1 & $3.37 \mathrm{E}-04$ & $9.0 \mathrm{E}-06$ \\
& 14.0 & $8.20 \mathrm{E}-04$ & $1.3 \mathrm{E}-05$ \\
& 16.1 & $1.39 \mathrm{E}-03$ & $3.8 \mathrm{E}-05$ \\
& 18.0 & $1.87 \mathrm{E}-03$ & $4.1 \mathrm{E}-05$ \\
& 20.0 & $2.34 \mathrm{E}-03$ & $4.2 \mathrm{E}-05$ \\
& 22.0 & $2.68 \mathrm{E}-03$ & $6.4 \mathrm{E}-05$ \\
\hline
\end{tabular}

Standard deviation; S.D. $=\sqrt{1 /(N-1) \sum_{i=1}^{N}\left(y_{i}-y_{\text {avg }}\right)^{2}}, N$ : number of repeated experiments 
Table 3

Solubilities of phenylbutazone (3) in supercritical carbon dioxide (1)

\begin{tabular}{llll}
\hline$T(\mathrm{~K})$ & $P(\mathrm{MPa})$ & $\mathrm{y}_{3}$ & S.D. \\
\hline 308.2 & 10.0 & $5.51 \mathrm{E}-04$ & $1.4 \mathrm{E}-05$ \\
& 12.0 & $8.20 \mathrm{E}-04$ & $9.7 \mathrm{E}-06$ \\
& 14.0 & $1.10 \mathrm{E}-03$ & $9.9 \mathrm{E}-06$ \\
& 16.1 & $1.39 \mathrm{E}-03$ & $2.2 \mathrm{E}-05$ \\
& 18.0 & $1.54 \mathrm{E}-03$ & $2.0 \mathrm{E}-05$ \\
& 20.0 & $1.77 \mathrm{E}-03$ & $4.5 \mathrm{E}-05$ \\
318.2 & 22.0 & $1.94 \mathrm{E}-03$ & $5.3 \mathrm{E}-05$ \\
& 10.0 & $1.60 \mathrm{E}-04$ & $1.7 \mathrm{E}-06$ \\
& 12.0 & $5.69 \mathrm{E}-04$ & $1.7 \mathrm{E}-05$ \\
& 14.0 & $9.67 \mathrm{E}-04$ & $2.0 \mathrm{E}-05$ \\
& 16.0 & $1.36 \mathrm{E}-03$ & $9.8 \mathrm{E}-06$ \\
& 18.0 & $1.69 \mathrm{E}-03$ & $1.6 \mathrm{E}-05$ \\
328.2 & 20.0 & $1.95 \mathrm{E}-03$ & $3.5 \mathrm{E}-05$ \\
& 22.0 & $2.23 \mathrm{E}-03$ & $4.7 \mathrm{E}-05$ \\
& 10.0 & $1.99 \mathrm{E}-05$ & $4.6 \mathrm{E}-07$ \\
& 12.0 & $2.47 \mathrm{E}-04$ & $6.3 \mathrm{E}-06$ \\
& 14.0 & $6.50 \mathrm{E}-04$ & $1.4 \mathrm{E}-05$ \\
& 16.1 & $1.22 \mathrm{E}-03$ & $3.2 \mathrm{E}-05$ \\
& 18.1 & $1.75 \mathrm{E}-03$ & $2.5 \mathrm{E}-05$ \\
& 20.0 & $2.20 \mathrm{E}-03$ & $5.1 \mathrm{E}-05$ \\
& 22.0 & $2.65 \mathrm{E}-03$ & $3.2 \mathrm{E}-05$
\end{tabular}

Standard deviation; S.D. $=\sqrt{1 /(N-1) \sum_{i=1}^{N}\left(y_{i}-y_{\text {avg }}\right)^{2}}, N:$ number of repeated experiments.

with increasing pressure along an isotherm for each solid compound. Nabumetone and phenylbutazone had similar solubility range from $10^{-4}$ to $10^{-3}$. Salicylamide showed lower solid solubility owing to its relatively higher melting temperature. The standard deviations (S.D.) for all data points were very small

Table 4

Solubilities of salicylamide (4) in supercritical carbon dioxide (1)

\begin{tabular}{llll}
\hline$T(\mathrm{~K})$ & $P(\mathrm{MPa})$ & $y_{4}$ & S.D. \\
\hline 308.2 & 10.2 & $5.57 \mathrm{E}-05$ & $1.6 \mathrm{E}-06$ \\
& 12.0 & $6.76 \mathrm{E}-05$ & $1.4 \mathrm{E}-06$ \\
& 14.1 & $7.48 \mathrm{E}-05$ & $1.9 \mathrm{E}-06$ \\
& 16.1 & $8.59 \mathrm{E}-05$ & $1.8 \mathrm{E}-06$ \\
& 18.1 & $9.64 \mathrm{E}-05$ & $1.7 \mathrm{E}-06$ \\
& 20.1 & $1.09 \mathrm{E}-04$ & $2.8 \mathrm{E}-06$ \\
& 22.0 & $1.16 \mathrm{E}-04$ & $2.3 \mathrm{E}-06$ \\
318.2 & 10.1 & $2.84 \mathrm{E}-05$ & $4.1 \mathrm{E}-07$ \\
& 12.0 & $6.45 \mathrm{E}-05$ & $4.4 \mathrm{E}-07$ \\
& 14.1 & $8.45 \mathrm{E}-05$ & $9.4 \mathrm{E}-07$ \\
& 16.0 & $1.08 \mathrm{E}-04$ & $1.9 \mathrm{E}-06$ \\
& 18.0 & $1.23 \mathrm{E}-04$ & $2.7 \mathrm{E}-06$ \\
& 20.0 & $1.42 \mathrm{E}-04$ & $3.1 \mathrm{E}-06$ \\
328.2 & 22.0 & $1.59 \mathrm{E}-04$ & $3.4 \mathrm{E}-06$ \\
& 10.0 & $8.45 \mathrm{E}-06$ & $2.1 \mathrm{E}-07$ \\
& 12.0 & $4.24 \mathrm{E}-05$ & $1.0 \mathrm{E}-06$ \\
& 14.1 & $8.78 \mathrm{E}-05$ & $2.4 \mathrm{E}-06$ \\
& 16.0 & $1.25 \mathrm{E}-04$ & $2.1 \mathrm{E}-06$ \\
& 18.0 & $1.54 \mathrm{E}-04$ & $2.6 \mathrm{E}-06$ \\
& 20.0 & $1.80 \mathrm{E}-04$ & $1.7 \mathrm{E}-06$ \\
& $2.10 \mathrm{E}-04$ & $6.0 \mathrm{E}-06$ \\
& &
\end{tabular}

Standard deviation; S.D. $=\sqrt{1 /(N-1) \sum_{i=1}^{N}\left(y_{i}-y_{\mathrm{avg}}\right)^{2}}, N$ : number of repeated experiments.

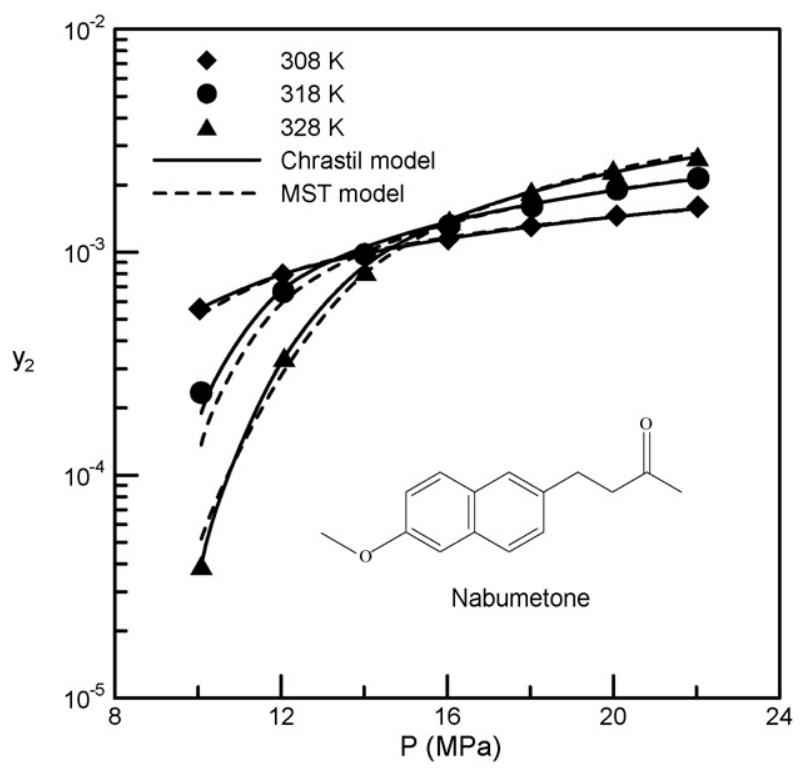

Fig. 3. Solubility for nabumetone (2) in supercritical carbon dioxide (1).

(Tables 2-4). The coefficient of variance, defined as (standard deviation/mean value), for the solid solubility measurements was below $3 \%$. These results indicated the repeatability of our experimental measurements. Graphical presentations are shown in Figs. 3-5, respectively. Temperature effect on the solid solubility was demonstrated by the presence of crossover points shown in these figures. The crossover pressures for nabumetone, phenylbutazone and salicylamide were determined at 15 , 17 and $13 \mathrm{MPa}$, respectively.

Two semi-empirical equations presented by Chrastil [11], and Mendez-Santiago and Teja [9] are commonly employed to correlate the solid solubility in supercritical $\mathrm{CO}_{2}$. The Chrastil model is expressed by a linear relationship between the logarithm of the solid solubility and the logarithm of the density of the pure

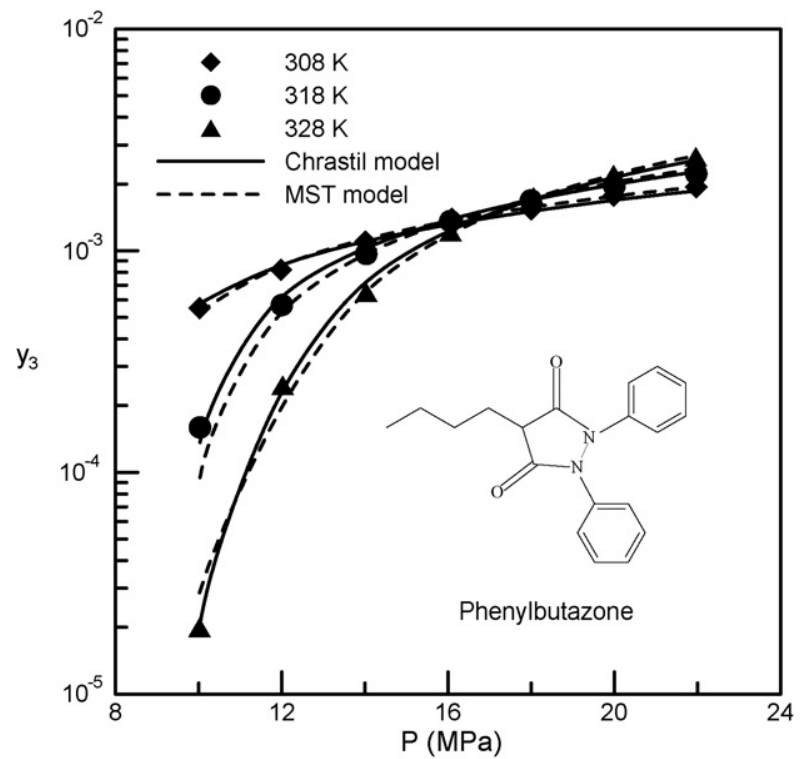

Fig. 4. Solubility for phenylbutazone (3) in supercritical carbon dioxide (1) 


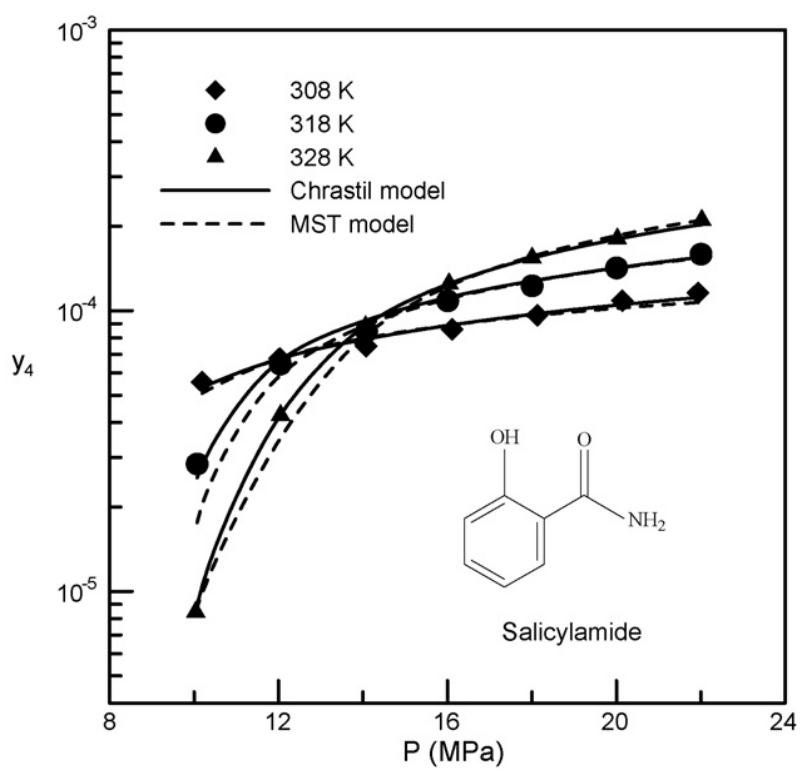

Fig. 5. Solubility for salicylamide (4) in supercritical carbon dioxide (1).

$\mathrm{CO}_{2}$ (component 1):

$\ln c_{j}=k \ln \rho_{1}+\frac{a}{T}+b$

where $c_{j}$ is the concentration of solute $j$ in supercritical fluid $\left(\mathrm{kg} / \mathrm{m}^{3}\right)$ and $\rho_{1}$ is the density of pure $\mathrm{CO}_{2}\left(\mathrm{~kg} / \mathrm{m}^{3}\right)$. The association number $k$ and the other two constants $a$ and $b$ were taken as three empirically fitted model parameters. These optimal parameters were determined by minimizing the following objective function in data regression:

Obj. $=\frac{100}{n} \sum_{k=1}^{n} \frac{\left|y_{j, k}^{\mathrm{exp}}-y_{j, k}^{\mathrm{cal}}\right|}{y_{j, k}^{\exp }}$

where the subscript $k$ denotes the $k$ th experimental data point for solid solute $j$.

Mendez-Santiago and Teja [9] developed another semiempirical equation, also with three parameters:

$T \ln \left(y_{j} P\right)=A+B \rho_{1}+C T$

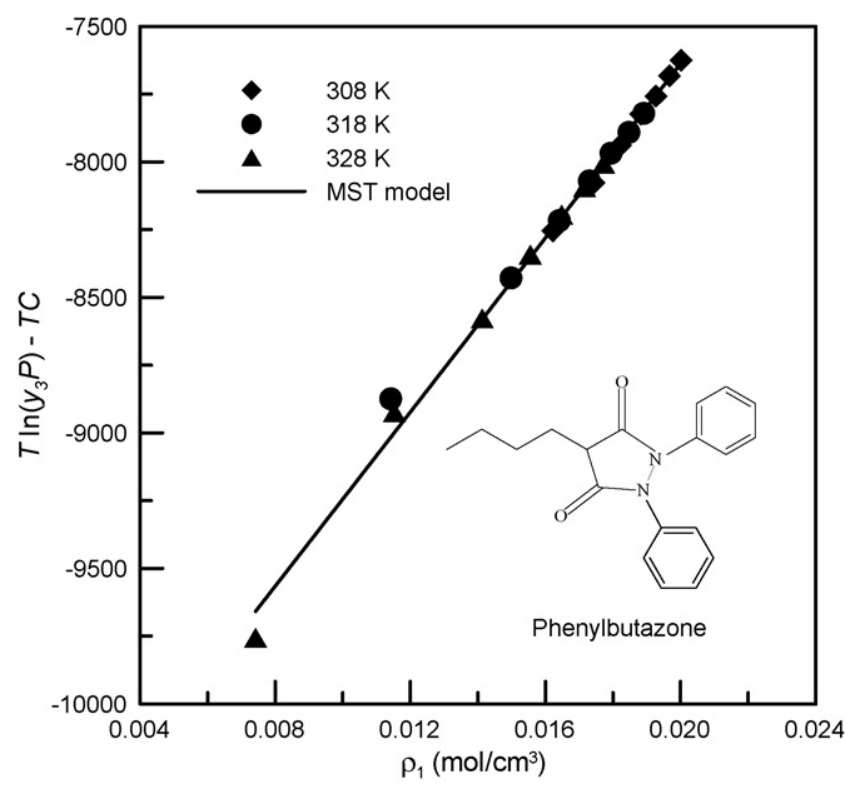

Fig. 6. Test of consistence for solubility data of phenylbutazone using MendezSantiago and Teja (MST) model.

The parameters ( $A, B$ and $C$ ) in Eq. (3) were optimally fitted in this study using the measured solid solubility data by minimizing the same objective function shown in Eq. (2).

The correlation results and optimally fitted parameters from these two semi-empirical equations are presented in Table 5. With the optimally fitted parameters, satisfactory accuracy for the calculated solid solubilities was observed from either equation with average absolute relative deviation below 7\%. The correlated results from the Chrastil equation and MendezSantiago and Teja equation (MST model) are graphically presented in Figs. 3-5. It was stated [9] that a self-consistency test can be examined for the experimental data using the MST model. A typical example is shown in Fig. 6 for phenylbutazone. The plot of $T \ln \left(y_{3} P\right)-T C$ against the density of supercritical $\mathrm{CO}_{2}$ is observed as a straight line. This result demonstrates that the parameters correlated using the MST model can be extrapolated to other temperatures. The similar results are observed for the other two solid compounds, and also for the Chrastil model.

Table 5

Correlated results of solid solubility data in supercritical carbon dioxide

\begin{tabular}{lll}
\hline Model & Parameters & \\
\hline $\mathrm{CO}_{2}(1)+$ nabumetone (2) & $k=5.9, a=-5.7374 \times 10^{3}, b=-19.6$ & 2.5 \\
$\quad$ Chrastil & $A=-1.1382 \times 10^{4}, B=1.5308 \times 10^{5}, C=25.9$ & \\
$\quad$ Mendenz-Santiago and Teja & & 5.9 \\
$\mathrm{CO}_{2}(1)+$ phenylbutazone (3) & $k=6.6, a=-5.0503 \times 10^{3}, b=-26.6$ & 4.2 \\
$\quad$ Chrastil & $A=-1.1032 \times 10^{4}, B=1.6958 \times 10^{5}, C=23.9$ & \\
Mendenz-Santiago and Teja & & 6.8 \\
$\mathrm{CO}_{2}(1)+$ salicylamide (4) & $k=4.7, a=-5.2633 \times 10^{3}, b=-15.8$ & 2.9 \\
Chrastil & $A=-1.0450 \times 10^{4}, B=1.2748 \times 10^{5}, C=21.9$ \\
$\quad$ Mendenz-Santiago and Teja & & 5.9 \\
\hline
\end{tabular}

$\operatorname{ARDY}(\%)=(100 / n) \sum_{k=1}^{n} \frac{\left|y_{j, k}^{\mathrm{exp}}-y_{j, k}^{\mathrm{cal}}\right|}{y_{j, k}^{\exp }}$, the summation is over all $k$ th experimental points for each solid $j$. 
Table 6

Data reference and physical properties for NSAIDs in this study

\begin{tabular}{|c|c|c|c|c|c|c|c|c|c|}
\hline Component & Formula & Mw $(\mathrm{kg} / \mathrm{mol})$ & $T$ range $(\mathrm{K})$ & $P$ range $(\mathrm{MPa})$ & Data points & $T_{\mathrm{m}}(\mathrm{K})$ & $\Delta H^{\mathrm{f}}(\mathrm{kJ} / \mathrm{mol})$ & $\begin{array}{l}\Delta U^{\mathrm{vap}, 298.15 \mathrm{~K}} \\
(\mathrm{~kJ} / \mathrm{mol})\end{array}$ & Reference \\
\hline Aspirin & $\mathrm{C}_{9} \mathrm{H}_{8} \mathrm{O}_{4}$ & 0.1802 & $308-328$ & $12-25$ & 24 & 407.36 & 23.01 & 82.24 & [24] \\
\hline Flurbiprofen & $\mathrm{C}_{15} \mathrm{H}_{13} \mathrm{FO}_{2}$ & 0.2443 & $303-323$ & $8-25$ & 27 & 383.90 & 21.68 & 105.29 & {$[25]$} \\
\hline Ibuprofen & $\mathrm{C}_{13} \mathrm{H}_{18} \mathrm{O}_{2}$ & 0.2063 & $308-318$ & $8-22$ & 29 & 349.15 & 19.72 & 85.46 & [26] \\
\hline Ketoprofen & $\mathrm{C}_{16} \mathrm{H}_{14} \mathrm{O}_{3}$ & 0.2543 & $313-332$ & $9-25$ & 25 & 367.15 & 20.74 & 116.96 & {$[27,28]$} \\
\hline Nabumetone & $\mathrm{C}_{15} \mathrm{H}_{16} \mathrm{O}_{2}$ & 0.2283 & $308-328$ & $10-22$ & 21 & 353.15 & 19.95 & 93.55 & $\mathrm{a}$ \\
\hline Naproxen & $\mathrm{C}_{14} \mathrm{H}_{14} \mathrm{O}_{3}$ & 0.2303 & $308-348$ & $9-36$ & 58 & 427.24 & 31.50 & 97.36 & {$[29,30]$} \\
\hline Nimesulide & $\mathrm{C}_{13} \mathrm{H}_{12} \mathrm{~N}_{2} \mathrm{O}_{5} \mathrm{~S}$ & 0.3083 & $313-332$ & $13-22$ & 8 & 421.65 & 23.82 & 116.46 & {$[28]$} \\
\hline Phenylbutazone & $\mathrm{C}_{19} \mathrm{H}_{20} \mathrm{~N}_{2} \mathrm{O}_{2}$ & 0.3084 & $308-328$ & $10-22$ & 21 & 378.58 & 21.38 & 130.94 & $\mathrm{a}$ \\
\hline Piroxicam & $\mathrm{C}_{15} \mathrm{H}_{13} \mathrm{~N}_{3} \mathrm{O}_{4} \mathrm{~S}$ & 0.3314 & $313-332$ & $10-22$ & 9 & 469.15 & 26.51 & 167.84 & {$[28]$} \\
\hline Salicylamide & $\mathrm{C}_{7} \mathrm{H}_{7} \mathrm{NO}_{2}$ & 0.1371 & $308-328$ & $10-22$ & 21 & 413.58 & 23.42 & 91.63 & a \\
\hline
\end{tabular}

${ }^{a}$ Solubility data measured in this study.

\subsection{Correlation of solubility for NSAIDs using the solution model approach}

Correlation of the solid solubility data for NSAIDs was also performed in this study using the solution model approach [12-14]. The supercritical fluid was assumed as a liquid where the nonideal behavior between the NSAID solute and $\mathrm{CO}_{2}$ was represented by an activity coefficient. The equilibrium solubility of solid solute (component $j$ ) in supercritical $\mathrm{CO}_{2}$ (component 1) is expressed as

$y_{j}=\frac{f_{j}^{\mathrm{s}}}{\gamma_{j}^{\infty} f_{j}^{1}}$

where $\gamma_{j}^{\infty}$ is the infinite dilution activity coefficient of the solid solute $j$ at its low solubility in the supercritical phase. $f_{j}^{\mathrm{s}}$ and $f_{j}^{l}$ are the fugacities of pure solute $j$ in the solid and supercritical phases, respectively. The ratio for these fugacities can be commonly approximated by:

$\ln \frac{f_{j}^{\mathrm{s}}}{f_{j}^{\mathrm{l}}}=\frac{\Delta H_{j}^{\mathrm{f}}}{R}\left(\frac{1}{T_{j, \mathrm{~m}}}-\frac{1}{T}\right)$

where $\Delta H^{\mathrm{f}}$ is the molar heat of fusion and $T_{\mathrm{m}}$ is the melting temperature. The infinite dilution activity coefficient was expressed by the modified regular solution model coupled with a Flory-Huggins term by Iwai et al. [12] and our previous studies $[13,14]$ :

$\ln \gamma_{j}^{\infty}=\left(\frac{v_{j}}{R T}\right)\left(\delta_{1}-\delta_{j}\right)^{2}+1-\left(\frac{v_{j}}{v_{1}}\right)+\ln \left(\frac{v_{j}}{v_{1}}\right)$

where $\delta$ is the solubility parameter and $v$ is the molar volume. Incorporating Eqs. (5) and (6), the solubility of a solid solute in the supercritical phase was:

$$
\begin{aligned}
\ln y_{j}= & \frac{\Delta H_{j}^{\mathrm{f}}}{R}\left(\frac{1}{T_{j, \mathrm{~m}}}-\frac{1}{T}\right)-\left(\frac{v_{j}}{R T}\right)\left(\delta_{1}-\delta_{j}\right)^{2}-1 \\
& +\left(\frac{v_{j}}{v_{1}}\right)-\ln \left(\frac{v_{j}}{v_{1}}\right)
\end{aligned}
$$

The melting temperature of solute, $T_{j, \mathrm{~m}}$, in Eq. (7) was taken from literature. The value of $\delta_{1}$ was evaluated using the
Peng-Robinson equation of state [18]. $\delta_{j}$ was calculated using the molar volume of the solute $\left(v_{j}\right)$ and the molar internal energy change of vaporization $\left(\Delta U_{j}^{\mathrm{vap}}\right)$. The latter was estimated by group contribution method developed by Fedor [19]. The molar heat of fusion, $\Delta H_{j}^{\mathrm{f}}$, was either taken from literature or estimated by the method of Yalkowsky [20]. The molar volume of supercritical carbon dioxide $\left(v_{1}\right)$ was estimated from the Jacobsen and Stewart equation of state with 32 constants regressed by Ely et al. [21]. Physical properties required for correlating the solubility data of NSAIDs in this study are listed in Table 6. The adjustable parameter $v_{j}$ was observed as a function of the density of $\mathrm{CO}_{2}$ in previous literatures [12-14]:

$\ln v_{j}=\alpha \ln \rho_{1}+\beta$

where $\rho_{1}$ was density of $\mathrm{CO}_{2}$, and $\alpha, \beta$ were two temperatureindependent adjustable parameters for each solid solute $j$. The optimal values of these two parameters were evaluated by minimizing the objective function shown in Eq. (2).

Incorporating Eq. (8) with Eq. (7), correlation of solid solubilities was denoted as the two-parameter model. Table 7 presents the optimally fitted parameters ( $\alpha$ and $\beta$ ) of the two-parameter model. The calculated average absolute relative deviation in solid solubility (ARDY) for 10 NSAIDs was $13.9 \%$. This

Table 7

Calculation results for the solubilities of NSAIDs in supercritical carbon dioxide

\begin{tabular}{|c|c|c|c|c|c|}
\hline \multirow[t]{2}{*}{ Component } & \multicolumn{2}{|c|}{$\begin{array}{l}\text { Two-parameter } \\
\text { model, Eq. (8) }\end{array}$} & \multicolumn{3}{|c|}{$\begin{array}{l}\text { One-parameter model } \\
(\beta=-13.03)\end{array}$} \\
\hline & $\alpha$ & $\beta$ & $\operatorname{ARDY}(\%)$ & $\alpha$ & $\operatorname{ARDY}(\%)$ \\
\hline Aspirin & -1.25 & -13.71 & 11.5 & -1.08 & 17.6 \\
\hline Flurbiprofen & -1.17 & -13.14 & 21.0 & -1.15 & 21.5 \\
\hline Ibuprofen & -1.03 & -12.60 & 16.7 & -1.13 & 32.6 \\
\hline Ketoprofen & -1.16 & -12.98 & 19.9 & -1.17 & 20.5 \\
\hline Nabumetone & -1.16 & -13.09 & 11.0 & -1.15 & 11.2 \\
\hline Naproxen & -1.17 & -13.22 & 14.5 & -1.13 & 16.9 \\
\hline Nimesulide & -1.12 & -12.75 & 20.0 & -1.18 & 24.9 \\
\hline Phenylbutazone & -1.18 & -12.70 & 6.7 & -1.26 & 29.7 \\
\hline Piroxicam & -1.20 & -12.58 & 8.1 & -1.31 & 33.6 \\
\hline Salicylamide & -1.23 & -13.49 & 5.7 & -1.12 & 18.2 \\
\hline Overall & & & 13.9 & & 21.3 \\
\hline
\end{tabular}
using the two-parameter and one-parameter models 


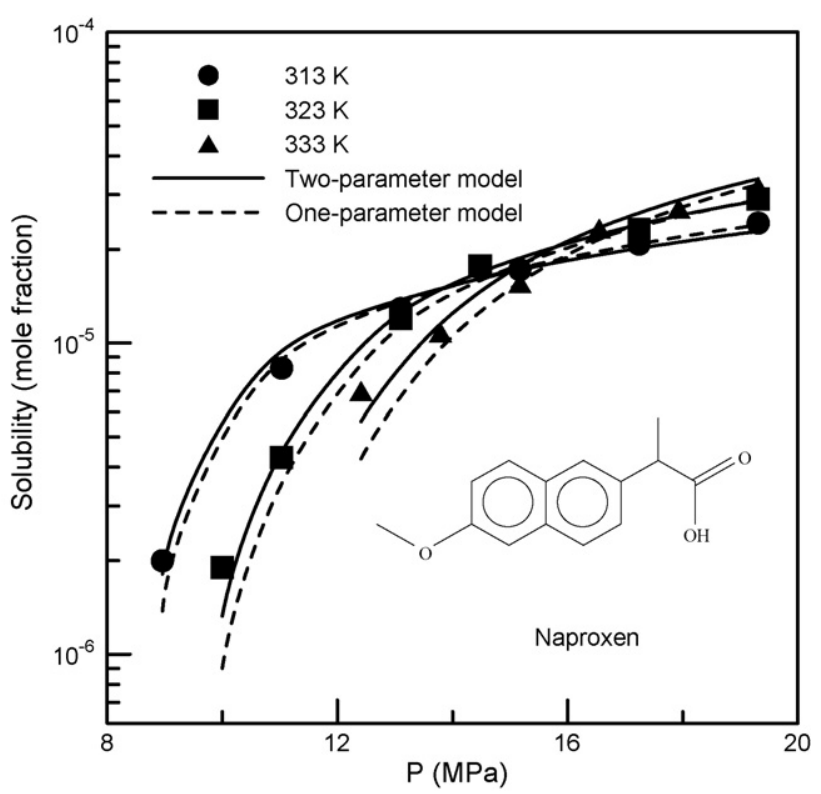

Fig. 7. Comparison of the experimental and calculated solid solubilities of naproxen in supercritical $\mathrm{CO}_{2}$ at various temperatures.

calculation error was within the range of experimental accuracy. A further simplification for the model parameters was attempted as presented in our previous study $[13,14]$ by reducing one model parameter. An average value of $\beta=-13.03$ was employed for 10 NSAIDs compounds in this study, and $\alpha$ was left as a single adjustable parameter. The results are shown in Table 7 as the one-parameter model with an ARDY of $21.3 \%$. Using only one parameter, it was observed that $70 \%$ of the calculated solid solubilities had ARDY less than $25 \%$. This calculated deviation can be considered as acceptable for these complex molecules. Fig. 7 shows the calculated solid solubility of naproxen using either the two- or one-parameter solution model in this study. The ARDY were $14.5 \%$ and $16.9 \%$ from each model, respectively. The results in Fig. 7 show that the solution model, with temperature-independent parameters, was feasible in correlating the experimental solubility data at various temperatures.

The single parameter $\alpha$ was further generalized in this study to make the solid solubility calculations predictable. A comparison of various predictive methods is shown in Table 8. In our previous studies, generalization of parameter $\alpha$ had been suggested. Cheng et al. [13] proposed a generalized equation that includes aromatic and biological compounds, and is cited as model I in Table 8. Su and Chen modified the generalized correlation of Cheng et al. [13], and presented an improved equation for $\alpha$ over 60 pharmaceutical solids. The equation recently demonstrated by Su and Chen [14] is taken as model II in Table 8. Applying either model I or model II for 10 NASIDs gave unsatisfactory results with high ARDY. Model II showed better results than model I because model II was obtained specifically for pharmaceutical compounds. Su and Chen [14] suggested that further correlation for $\alpha$ could be investigated for various groups of compounds with specific functions. For the NSAIDs, we tried a new correlation of $\alpha$. Fig. 8 shows a plot of the best-fitted $\alpha$ values for each NSAID in the one-parameter model against
Table 8

Prediction of solid solubilities of NSAIDs in supercritical carbon dioxide using various models

\begin{tabular}{|c|c|c|c|c|}
\hline \multirow[t]{3}{*}{ Component } & \multicolumn{4}{|c|}{ Predictive model $^{\mathrm{a}}$} \\
\hline & I & II & III & IV \\
\hline & ARDY (\%) & ARDY (\%) & ARDY (\%) & ARDY $(\%)$ \\
\hline Aspirin & 424.7 & 21.3 & 36.3 & 18.6 \\
\hline Flurbiprofen & 241.4 & 100.9 & 23.1 & 28.6 \\
\hline Ibuprofen & 38.4 & 84.9 & 82.9 & 59.7 \\
\hline Ketoprofen & 159.3 & 158.0 & 22.0 & 27.6 \\
\hline Nabumetone & 28.3 & 74.1 & 80.3 & 15.2 \\
\hline Naproxen & 232.7 & 55.2 & 17.2 & 24.3 \\
\hline Nimesulide & 35.1 & 30.8 & 49.7 & 29.0 \\
\hline Phenylbutazone & 94.8 & 92.2 & 97.2 & 30.1 \\
\hline Piroxicam & 55.3 & 26.7 & 37.3 & 33.6 \\
\hline Salicylamide & 166.5 & 21.9 & 29.6 & 19.7 \\
\hline Overall & 173.5 & 71.2 & 43.3 & 28.6 \\
\hline $\begin{array}{l}{ }^{\text {a }} \text { Models, } \quad \text { I: } \\
\beta=-12.89 ; \quad \alpha \\
\alpha=-0.8712-0.0 \\
\text { using one experin }\end{array}$ & $\begin{array}{l}\beta=-13.26 \\
0.3579-0.3185 \\
2616 \Delta U_{j}^{\text {vap }} \text { (th } \\
\text { ental data point }\end{array}$ & $\begin{array}{l}\alpha=-0.9517 \\
\qquad \ln \Delta U_{j}^{\text {vap }} \\
\text { s study), IV: } \\
\text { at the lowest }\end{array}$ & $\begin{array}{l}.002173 \Delta U_{j}^{\text {vap }} \\
{[14], \quad \text { III: }} \\
=-13.03 ; \alpha \text { wa }\end{array}$ & $\begin{array}{r}{[13], \quad \text { II: }} \\
\beta=-13.03 ; \\
\text { as calculated }\end{array}$ \\
\hline
\end{tabular}

the physical properties $\Delta U_{j}^{\mathrm{vap}}$. A nearly linear relationship was observed:

$\alpha=-0.8712-0.002616 \Delta U_{j}^{\text {vap }}$

The correlation Eq. (9) is cited as model III in Table 8. The predicted results from model III had an ARDY of $43.3 \%$ that was significantly improved over models I and II. The distribution of calculated errors from model III was also satisfactory. Over $70 \%$ of the predicted solid solubilities had ARDY less than 50\%. Prediction and comparison for solid solubility of salicylamide in supercritical $\mathrm{CO}_{2}$ is shown in Fig. 9. The ARDY for

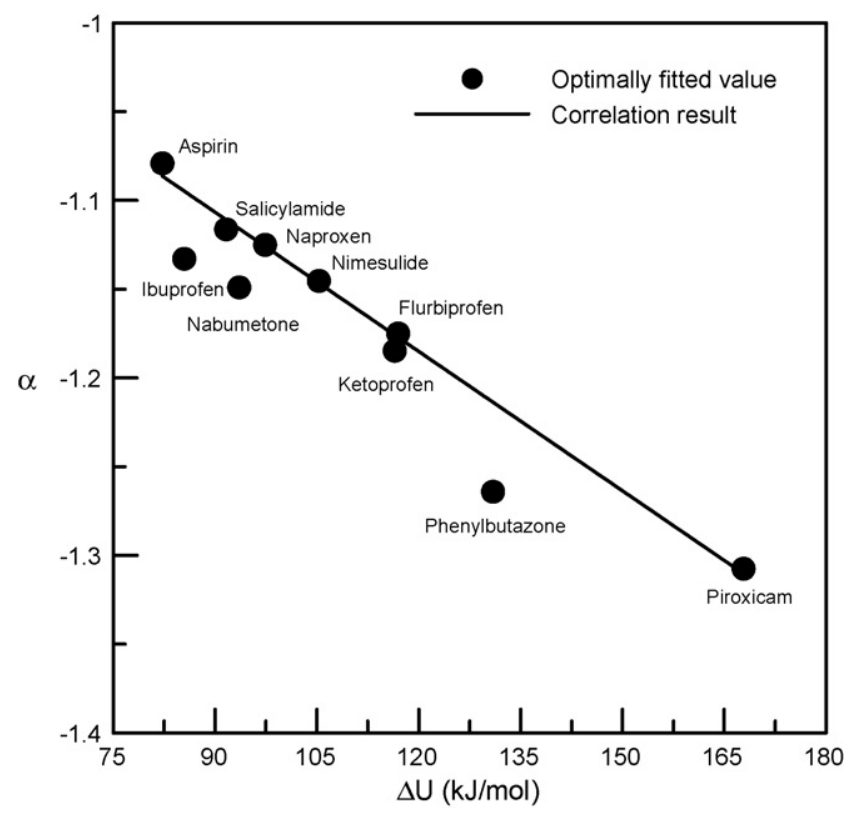

Fig. 8. Plot of the optimally fitted $\alpha$ values against the internal energy change of vaporization for various NSAIDs. 


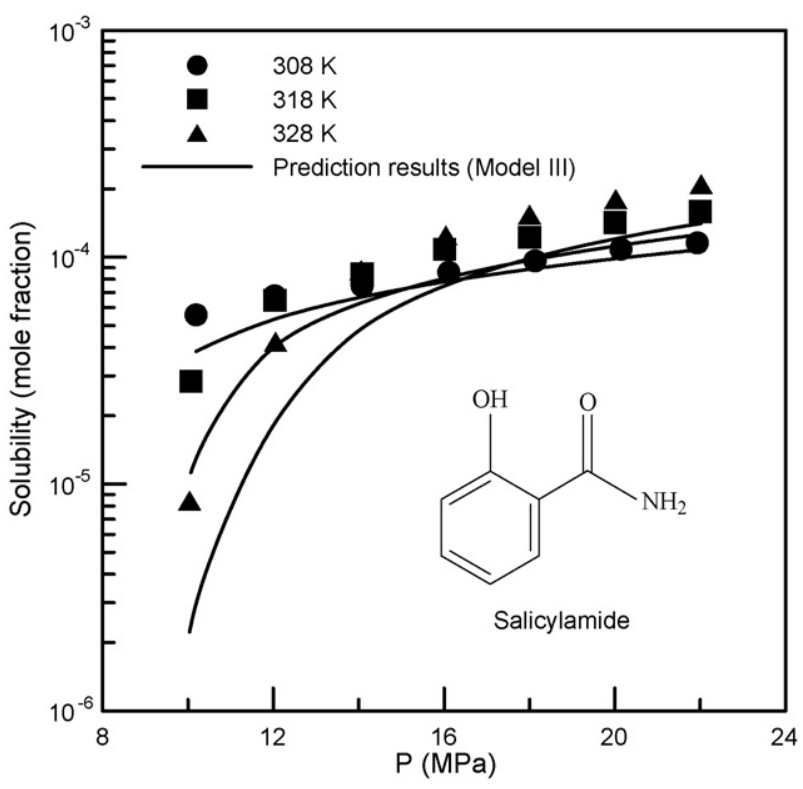

Fig. 9. Predicted solid solubility of salicylamide in supercritical $\mathrm{CO}_{2}$ using the generalized correlation of $\alpha$ in this study.

this system was $29.6 \%$ over three temperatures. The predicted solid solubility showed larger deviation at the low-pressure end. The solubilities at high pressures were predicted with acceptable accuracy.

Three NSAIDs of ibuprofen, nabumetone and phenylbutazone showed ARDY higher than $80 \%$ from model III in Table 8. This indicates that further improvement of model III can be investigated. It is suggested to apply the one-parameter model but the $\alpha$ parameter was determined using only one experimental data point. This approach is cited as model IV in Table 8, in which the $\alpha$ parameter was evaluated by one experimental data point at the lowest temperature and pressure for each solid

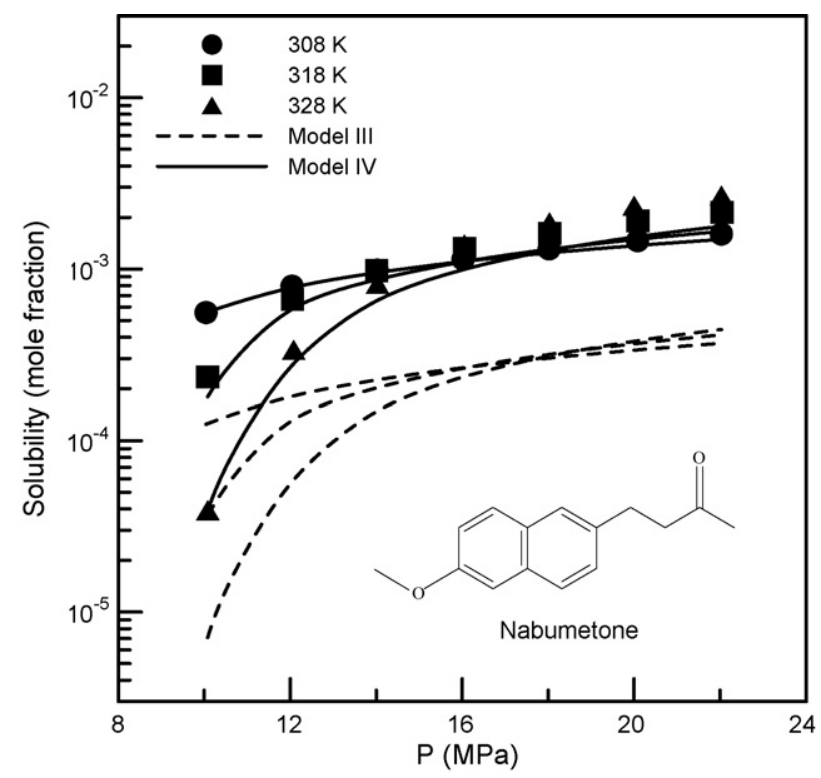

Fig. 10. Comparison for the predicted solid solubility of nabumetone in supercritical $\mathrm{CO}_{2}$ using two predictive models. compound. It is presented in Table 8 that the overall ARDY from model IV was $28.6 \%$, and was comparable to that from the correlative one-parameter model. As shown in Table 8, the calculated ARDY of phenylbutazone decreased from $97.2 \%$ in model III to $30.1 \%$ in model IV. Fig. 10 shows graphically the improvement for nabumetone. It depicts that using the solution model and only limited experimental information, the solid solubilities in supercritical $\mathrm{CO}_{2}$ can be predicted over extended temperatures and pressures with acceptable accuracy.

\section{Conclusion}

New solid solubility data for three NSAIDs of nabumetone, phenylbutazone and salicylamide in supercritical $\mathrm{CO}_{2}$ are presented in this study at 308.2, 318.2 and 328.2 K over the pressure range from 10 to $22 \mathrm{MPa}$. Nabumetone and phenylbutazone had similar solubility range of $10^{-4}$ to $10^{-3}$. Salicylamide showed lower solid solubility owing to its relatively higher melting temperature. Satisfactory correlation results for solid solubilities were observed using the Chrastail or Mendez-Santiago and Teja semi-empirical equations where the average absolute relative deviation in solid solubility (ARDY) was below 7\%. The solution model was applied to correlate the solid solubilities of these three compounds and seven other NSAIDs. With two temperature-independent parameters for each system, the calculated ARDY was $13.9 \%$. These parameters were further generalized and the overall predicted error was $43.3 \%$ (model III). It was finally demonstrated that with only one experimental data, the solution model parameters were satisfactorily adjusted (model IV). Model IV yielded an ARDY of $28.6 \%$ for 10 NSAIDs over extended temperature and pressure ranges.

\section{Acknowledgement}

The authors are grateful to the National Science, ROC, for supporting this study.

\section{References}

[1] A.S. Teja, C.A. Eckert, Commentary on supercritical fluids: research and application, Ind. Eng. Chem. Res. 39 (2000) 4442-4444.

[2] E.J. Beckman, Supercritical and near-critical $\mathrm{CO}_{2}$ in green chemical synthesis and processing, J. Supercrit. Fluid 28 (2004) 121-191.

[3] P. York, Strategies for particle design using supercritical fluids technology, Pharm. Sci. Technol. Today 2 (1999) 430-440.

[4] J. Jung, M. Perrut, Particle design using supercritical fluids: literature and patent survey, J. Supercrit. Fluid 20 (2001) 179-219.

[5] E. Reverchon, G. Della Porta, Particle design using supercritical fluids, Chem. Eng. Technol. 26 (2003) 840-845.

[6] I. Pasquali, R. Bettini, F. Giordano, Solid-state chemistry and particle engineering with supercritical fluids in pharmaceutics, Eur. J. Pharm. Sci. 27 (2006) 299-310.

[7] F.P. Lucien, N.R. Foster, Solubilities of solid mixtures in supercritical carbon dioxide: a review, J. Supercrit. Fluid 17 (2000) 111-134.

[8] O. Guclu-Ustundag, F. Temelli, Correlating the solubility behavior of fatty acid, mono-, di, and triglycerides, and fatty acid esters in supercritical carbon dioxide, Ind. Eng. Chem. Res. 39 (2000) 4756-4766.

[9] J. Mendez-Santiago, A.S. Teja, The solubility of solids in supercritical fluids, Fluid Phase Equilibr. 158-160 (1999) 501-510. 
[10] K.W. Cheng, M. Tang, Y.P. Chen, Solubilities of benzoin, propyl 4hydrozybenzoate and mandelic acid in supercritical carbon dioxide, Fluid Phase Equilibr. 201 (2002) 79-96.

[11] J. Chrastil, Solubility of solids and liquids in supercritical gases, J. Phys. Chem. 86 (1982) 3016-3021.

[12] Y. Iwai, Y. Koga, T. Fukuda, Y. Arai, Correlation of solubilitues of highboiling components in supercritical carbon dioxide using a solution model, J. Chem. Eng. Jpn. 25 (1992) 757-760.

[13] J.S. Cheng, M. Tang, Y.P. Chen, Correlation of solid solubility for biological compounds in supercritical carbon dioxide: comparative study using solution model and other approaches, Fluid Phase Equilibr. 194-197 (2002) 483-491.

[14] C.S. Su, Y.P. Chen, Correlation for the solubilities of pharmaceutical compounds in supercritical carbon dioxide, Fluid Phase Equilibr. 254 (2007) $167-173$.

[15] A. Stassi, R. Bettini, A. Gazzaniga, F. Girodano, A. Schiraldi, Assessment of solubility of ketoprofen and vanillic acid in supercritical $\mathrm{CO}_{2}$ under dynamic conditions, J. Chem. Eng. Data 45 (2000) 161-165.

[16] G.S. Gurdial, N.R. Foster, Solubility of $o$-hydroxybenzoic acid in supercritical carbon dioxide, Ind. Eng. Chem. Res. 30 (1991) 575-580.

[17] E. Reverchon, G. Donsi, Salicylic acid solubilization in supercritical $\mathrm{CO}_{2}$ and its micronization by RESS, J. Supercrit. Fluid 6 (1993) 241-248.

[18] D.Y. Peng, D.B. Robinson, A new two-constants equation of state, Ind. Eng. Chem. Fundam. 15 (1976) 59-64.

[19] R.F. Fedors, A method for estimating both the solubility parameters and molar volume of liquids, Pol. Eng. Sci. 14 (1974) 147-154.

[20] S.H. Yalkowsky, Estimation of entropies of fusion of organic compounds, Ind. Eng. Chem. Fundam. 18 (1979) 108-111.
[21] J.F. Ely, W.M. Haynes, B.C. Bain, Isochoric $\left(P, V_{\mathrm{m}} T\right)$ measurements on $\mathrm{CO}_{2}$ and on $\left(0.982 \mathrm{CO}_{2}+0.018 \mathrm{~N}_{2}\right)$ from 250 to $330 \mathrm{~K}$ at pressure to $35 \mathrm{MPa}$, J. Chem. Thermodyn. 21 (1989) 879-894.

[22] M.J. O'Neil, The Merck Index, 13th ed., Merck \& Co., Inc., Whitehouse Station, NJ, 2001.

[23] Website of Sigma-Aldrich company, http://www.sigmaaldrich.com.

[24] Z. Huang, W.D. Lu, S. Kawi, Y.C. Chiew, Solubility of aspirin in supercritical carbon dioxide with and without acetone, J. Chem. Eng. Data 49 (2004) 1323-1327.

[25] A.R.C. Duarte, P. Coimbra, H.C. de Sousa, C.M.M. Duarte, Solubility of flurbiprofen in supercritical carbon dioxide, J. Chem. Eng. Data 49 (2004) 449-452.

[26] M. Charoenchaitrakool, F. Dehghani, N.R. Foster, H.K. Chan, Micronization by rapid expansion of supercritical solutions to enhance the dissolution rates of poorly water-soluble pharmaceuticals, Ind. Eng. Chem. Res. 39 (2000) 4794-4802.

[27] A. Stassi, R. Bettini, A. Gazzaniga, F. Giordano, A. Schiraldi, Assessment of solubility of ketoprofen and vanillic acid in supercritical $\mathrm{CO}_{2}$ under dynamic conditions, J. Chem. Eng. Data 45 (2000) 161-165.

[28] S.J. Macnaughton, I. Kikic, N.R. Foster, P. Alessi, A. Cortesi, I. Colombo, Solubility of anti-inflammatory drugs in supercritical carbon dioxide, J. Chem. Eng. Data 41 (1996) 1083-1086.

[29] A. Garmroodi, J. Hassan, Y. Yamini, Solubilities of the drugs benzocaine, metronidazole benzoate and naproxen in supercritical carbon dioxide, J. Chem. Eng. Data 49 (2004) 709-712.

[30] S.S.T. Ting, S.J. Macnaughton, D.L. Tomasko, N.R. Foster, Solubility of naproxen in supercritical carbon dioxide with and without cosolvent, Ind. Eng. Chem. Res. 32 (1993) 1471-1481. 